\title{
EFFECT OF THE SHAPE AND STRUCTURE OF MATURITY SENSOR'S PLASTIC HOUSING ON ITS PHYSICO-MECHANICAL PROPERTIES
}

\author{
Utepov Ye.B. ${ }^{1,2}$, Akhazhanov S.B. ${ }^{3}$, Aniskin A. ${ }^{4}$, Zharassov Sh.Zh. ${ }^{1, *}$ \\ 'L.N. Gumilyov Eurasian National University, Nur-Sultan, Kazakhstan, zhshzh95@gmail.com \\ ${ }^{2}$ CSI Research\&Lab, LLP, Nur-Sultan, Kazakhstan \\ ${ }^{3}$ Buketov Karaganda University, Karaganda, Kazakhstan \\ 4 University North, Varaždin, Croatia
}

\begin{abstract}
This paper presents how the shape and physical structure of the connections affect the performance of the housing of maturity sensor. A two parts rectangular and a keg-shaped cylindrical configurations of plastic housings were sequentially tested for water, shock and load resistance. The tests revealed the weak ingress and shock resistance of the rectangular housing, in comparison with cylindrical one, where no serious defects were identified. Both types of housings performed well during the compression tests on all three sides, showing the bearing capacities from 0.6 to $2.11 \mathrm{kPa}$, which are equivalent to 65.3 and $165.3 \mathrm{~kg}$ of human mass. Based on the results, the study demonstrates an easy-to-handle workflow for generic testing and evaluation of maturity sensors housing. The proposed workflow may be applicable for other types of small-scaled electronic devices.
\end{abstract}

Keywords: non-destructive testing method, concrete sensor, housing, durability, maturity sensor.

\section{Introduction}

The indoor electronic devices used in daily routine are not subjected to adverse conditions, unlike those used outdoor. The latter should comply with higher requirements, having a protected housing. The housing of such devices must stand for various aggressive environment [1,2]. Depending on the type of device, their housing may be built of different materials as metal, aluminum, timber, plastic, etc. [3]. First three take much efforts to treatment and finishing, especially when it comes to small devices. Moreover, their large-scale production requires significant human and financial resources. Therefore, plastic housings have found broad application in small-sized instrumentation [3]. Despite this, the requirements for them are not a little less. This means the plastic housings should have certain physical and mechanical properties. And again, depending on the type of device they are used for, the list of such properties may vary a lot [4]. The maturity sensors [5-8], which will be discussed in this study, represent small electronic devices with the protected housing. Due to they are embedded into the concrete body, they are subjected to moist, alkaline, and pressurized environment [9].

Since a minor water penetration inside the housing through cracks or slots in the connectors may destroy their inner electronic components. Moreover, while being strapped to a rebar, they are subjected to a shock impact from the pouring concrete mixture [10].In addition, before the installation, the maturity sensors may be accidentally stepped by workers. Therefore, to confront potential external impact, the housing of maturity sensors must have specific physical and mechanical properties complying with the requirements of $[11,12]$. Some important aspects influencing the characteristics of the plastic housing are its shape and structure [13]. If referring to the existing analogs of maturity sensors [1,2], their housings mostly have rectangular shape. They classically consist of two components joining together with screws and nuts with rubber gasket in between. Few have monolithic housing [1], which makes them indestructible.

Despite the variety in shape and structure of the housings of existing maturity sensors, the majority of them have not strayed far from conventional solutions. Since no previous works were found studying the performance of the maturity sensors housing depending on its shape and structure. This suggests that the mature sensor manufacturers relied only on logical assumptions when designing the housings. Perhaps, this is due to insignificance of the production scale of maturity sensors in contrast with major industries of the national economy, where every single detail counts. For example, the automotive and aviation industry pays a lot of attention to the shape of the vehicles, structures of connections, and so on [14, 15]. Nevertheless, the application of maturity sensors is becoming more and more popular in construction sites worldwide [16]. 
And therefore, more and more issues related to the shape and their housing structure arises, which indicates to the relevance of this topic.

In view of the foregoing, this article studies the impact of the shape and structure on the physical and mechanical properties of the maturity sensors housing made of plastic. The following physical and mechanical properties are of interest: water resistance, shock resistance, and compressive strength. These properties were chosen due to the maturity sensors are subjected most to water ingress, drop of concrete while pouring, and squeeze while concrete hardening.

\section{Materials and methods}

To discover the effect of the shape and structure on the performance of plastic housing of the maturity sensor, two configurations of the housings were designed: 1) Two parts rectangular;2) Keg-shaped cylindrical. Two-component liquid plastic from the company Kimpur - Kimteks Kimya Teksti lÜrünlerive Ticaret A.Ş. formed the basis of the housings. This type of plastic is characterized by its hardness, resistance to mechanical influences, and short setting time. The components of this plastic were mixed in a 1:1 ratio by weight [17]. Both types of housings went through the major stages of design, prototyping, and replication. The wall thickness of housings was fall within the range between 1.5 and $5 \mathrm{~mm}$, depending on the part of the housing body. The prototyping was made with $3 \mathrm{D}$ printer. Then the prototypes were polished and used to mold the master formworks for replication. The master formworks were made of the two-component silicone HY-520 produced by the Shenzhen Hong Ye Jie Technology Co., mixed with a hardener in the ration of 1:40 by weight [18]. A distinctive feature of the cylindrical housing was the inner structure of its cap, which helped excluding any usage of the gaskets for hydro insulation (Figure 1), like in the plastic bottle caps.



Fig.1. Design of the cylindrical housing

To test for water resistance, both types of housings were sealed with tissue paper inside and prepared for complete submerging in a tank of water [11], where they supposed to remain for 1 month. The tissue paper was planned to be used as an indicator of water proofness of the housings. To prevent them from floating to the surface, they were loaded with weights. The samples were checked on a daily basis till the water penetration is detected. The shock resistance of the housings is tested by a procedure of free-fall from the different heights $(1,1.5$ and $2 \mathrm{~m})$ according to [19]. Three samples of each type of housings were used for testing. Due to the complexity of the technical evaluation after dropping, a visual inspection of the samples condition was performed according to the [20] principle (identification of scratches, cracks, and destructions). The compression strength tests were carried out on three sides of the housings as shown in the Figure 2, according to [12].

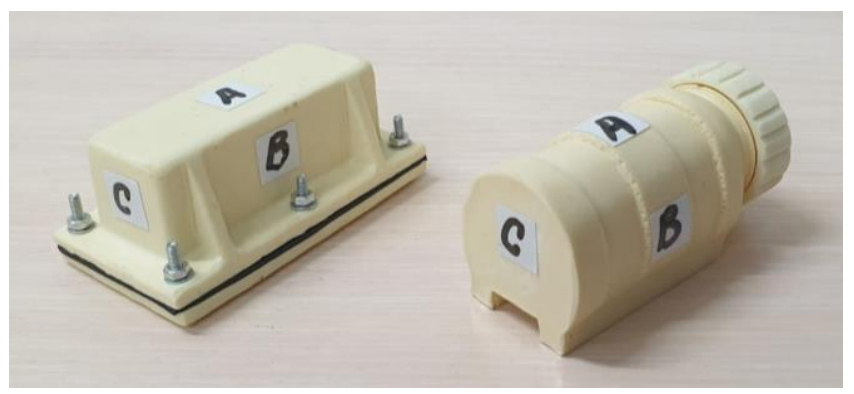

Fig.2. Compression load sides: left - rectangular housing; right -cylindrical housing 
The compression load was subjected by an electromechanical press-machine UNIFRAME 70-T1182 with a load range up to $50 \mathrm{kN}$ and displacement speed ranging from 0.05 to $51 \mathrm{~mm} / \mathrm{min}$. The measurements of the load resistance were taken each 2 seconds. The rectangular and cylindrical housing samples three each were destroyed during the compression tests. The load was transmitted with a constant speed of $5 \mathrm{~mm}$ per minute before cracking. This moment is characterized with the rapid drop of the resistance value. While calculating the strength, different nozzle area of the press piston was taken into account.

\section{Results and discussion}

The water-resistance test revealed the weakness of rectangular housing that failed the test at 3 days of submerging, which was confirmed by the blotting of the paper inside. Meanwhile, the cylindrical housing remained in the tank of water for 1 month, turned out to be completely waterproof, since the paper inside after the inspection still remained dry (Figure 3).

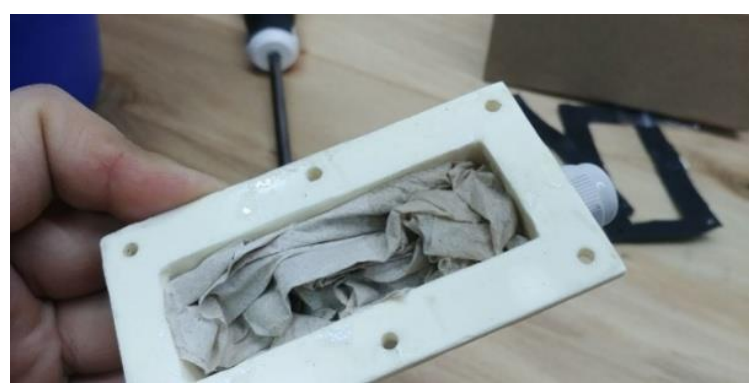

a)

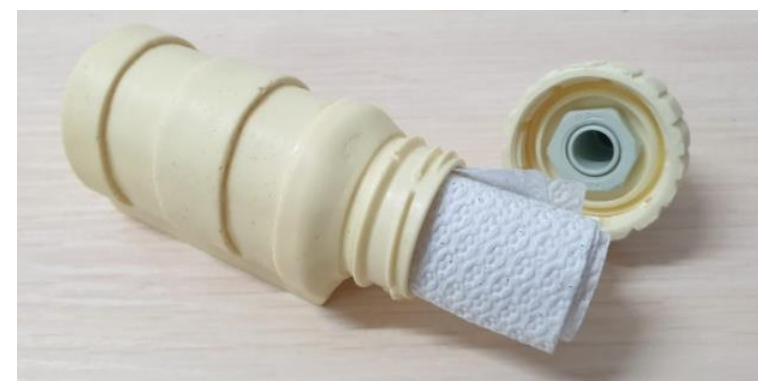

b)

Fig.3. Water-resistance test results: a) wet paper in the rectangular housing; b) dry paper in the cylindrical housing.

From the picture above is seen that the water mainly penetrated through the gaps in-between the rubber gasket and the two parts of the rectangular housing tightened with screws and nuts. Perhaps, when tightening, the plastic curved a bit and the gaps occurred. However, still this indicates unreliability of such structure of the rectangular housing, especially its joints. The cylindrical housing in contrast has a smaller number of joints. And therefore, has less chance to let the water run inside. Moreover, the clamping mechanism of the cap worked well. The shock resistance test results are shown in the Figure 4 below.

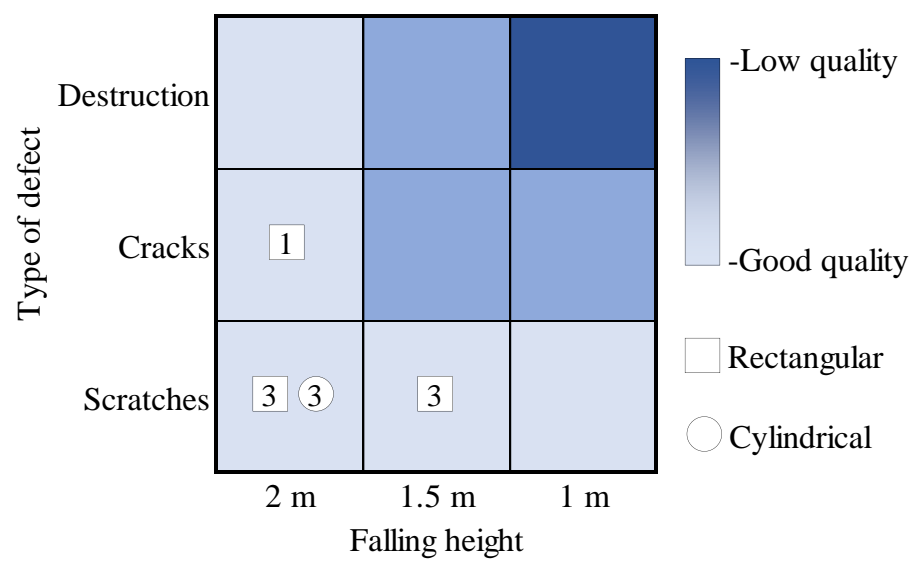

Fig.4. Results of shock resistance test of the housings as quality matrix

As is seen from the figure above, the tests did not cause notable damage on all the samples of both types of housings; no destructions were identified. After the tests the quality of the housings stood rather good. There were minor scratches on the surface of the samples, as well as a single crack in one of the samples of rectangular housing that fall from a height of $2 \mathrm{~m}$. The rectangular housing was cracked at the screw connection part, which may be reasoned by the fact that the screw holes were located close to the edge of the housing. The results of compression test of the housings are demonstrated below (Figure 5). 


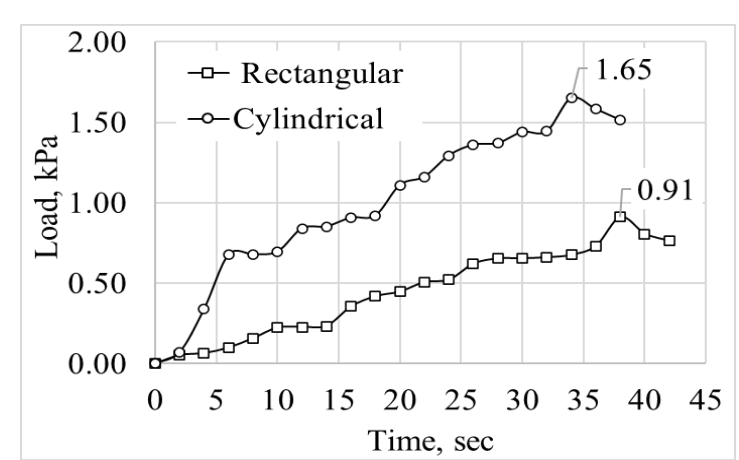

a)

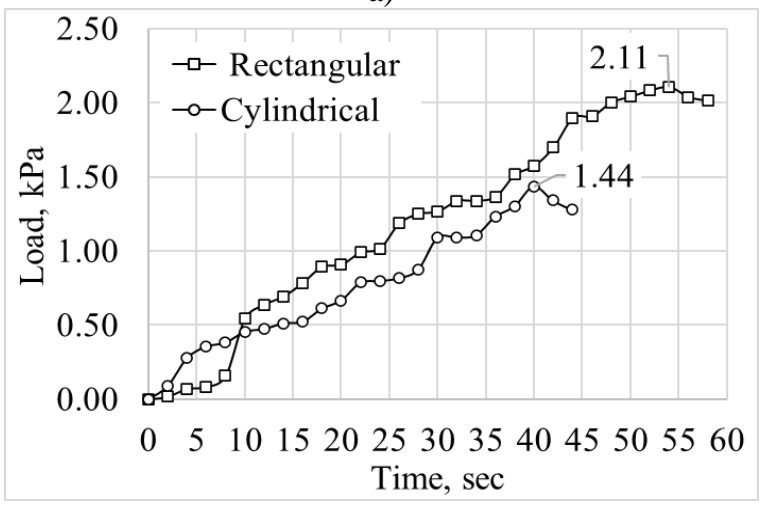

c)

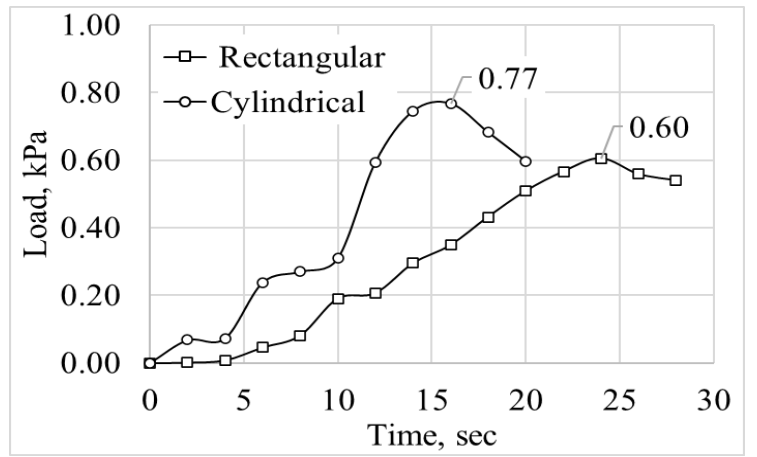

b)



d)

Fig.5. Compression test results of the housings: a) A-sides; b) B-side; c) C-side; d) Comparison

The diagrams above show that the cylindrical housing generically may bear more loads than those of rectangular one. It was ahead on the sides A and B of the housings, but lower in side C. The latter was predictable due to the thinness of wall thickness in the threaded part. The maximum loads that the rectangular and cylindrical housings could bear for sides A, B, and Care arranged in the following order: $0.91,0.6,2.11 \mathrm{kPa}$ and $1.65,0.77,1.44 \mathrm{kPa}$ respectively. While the average load amounted $1.25 \mathrm{kP}$, only side $\mathrm{A}$ and $\mathrm{C}$ of the cylindrical, and side $\mathrm{C}$ of rectangular housing could exceed this level. Thus, the sides of the housings when ranked by bearing load may be given the following comparison: $\mathrm{B}<\mathrm{A}<\mathrm{C}$ for the rectangular shape, $\mathrm{B}<\mathrm{C}<\mathrm{A}$ for the cylindrical shape.

To sum up, both housings demonstrated fairly acceptable performance. However, the cylindrical housing turned out to be more reliable. Moreover, the keg-shaped cylindrical housing turned out to be $100 \%$ waterproof according to the test results, less cost and labor-intensive due to the exclusion of screw connections and rubber for waterproofing. It seen from the results of the study that the small changes of the structure and shape of the housings may significantly affect their physical and mechanical properties. For example, as it turned out, when using plastic materials to develop the housing, the hydro insulation with rubber and the screw tightening may be omitted. This eases the structural schema of the housing and saves the resources. In this regard, the proposed keg-shaped cylindrical housing with the screw cap may have some advantages with those of the housing of its existing analogues [1,2]. The workflow formed for versatile testing and used to custom designs of the maturity sensors housings may be applicable for some other smallscaled electronic devices that are exposed to submergence and various loads, including homemade and (or) professional ones. Further work will be focused on testing the developed housings for melt in acid and alkaline environment, as well as for the various temperature conditions, including flame ignition.

\section{Conclusion}

To reveal the effect of the shape and structure of the housing of maturity sensors on its physical and mechanical properties, two configuration of housings were manufactured: the two-part rectangular and kegshaped cylindrical. Both types of housing were tested for water, shock, and compression load from three sides. Of course, besides the mentioned properties, the housings may be additionally tested for, such parameters as transparency, quality to the touch, tearing, floatability, flammability, flame color, smell when burning, and solubility in liquids and scratching. However, these parameters were not important the concrete 
maturity sensors housing. But may be important for the housings of other types of devices. Based on the results of the tests performed the following statements may be concluded:

- the shape and structure of the housing may significantly influence on its physical characteristics, such as its mass, free space inside, resources used for joints.

- small modifications of the structure of the joints may remarkably improve the water resistance of the housing;

- the monolithic design of the container part and the small number of parts in general in the assembly provides more structural robustness to the housing;

- the keg-shaped cylindrical housing appeared to be more reliable than those of rectangular one in several aspects, and could preserve its physical and mechanical properties in an acceptable level.

The workflow provided in the study and aimed on prompt verification of physical and mechanical properties of the housings, may be applied for various small and multi-scale electronic products.

\section{Acknowledgments \\ This research was funded by the Science Committee of the Ministry of Education and Science of the Republic of Kazakhstan (Grant № AP08956209).}

\section{REFERENCES}

1 Giatec. Wireless SmartRockTM Concrete Sensors Keep Construction Workers Safe During Pandemic. Available at: https://www.prnewswire.com/news-releases/wireless-smartrock-concrete-sensor (13.09.2021).

2 Olson C. iButton Link Sensors Complete Space Mission 2021. Available at: https://cdn.shopify.com/s/files/1/0164/3524/files/iButtonLink-Rhodium-NASA_NG-14_FINAL (13.09.2021).

3 Weichel C. Enclosed: a component-centric interface for designing prototype enclosures. Proceedings of the 7th Intern. Conf. on Tangible, Embedded and Embodied Interaction - TEI '132013. pp. 215-218.

4 Roger B. Requirements for physical testing of rubbers and plastics. Polymer Testing. 1984, Vol. 4, No. 24, pp. 91-100. doi: 10.1016/0142-9418(84)90003-5

5 Utepov Ye.B., Tulebekova A.S., Zharassov Sh.Zh., Bazarbayev D. Development of a case for a wireless sensor for monitoring of reinforced concrete structures. Bulletin of Kazakh Leading Academy of Architecture and Construction. 2021, Vol. 80, No. 2, pp. 264-274. doi: https://doi.org/10.51488/1680-080X/2021.2-06

6 Utepov Ye.B., et al. Development of an IT architecture for a wireless sensor for monitoring the strength of reinforced concrete structures. Herald of the Kazakh - British technical university. 2021, Vol. 18, No. 1, pp. $168-175$.

7 Utepov Ye.B., Khudaibergenov O.A., Kabdush Ye.B., Kazkeev A.B. Prototyping an embedded wireless sensor for monitoring reinforced concrete structures. Computers and Concrete. 2019, Vol. 24, No. 2, pp. 95-102.

8 Utepov Ye.B., Aniskin A., Ibrashov A.P., Tulebekova A.S. Maturity sensors placement based on the temperature transitional boundaries. Magazine of Civil Engineering. Vol. 90, No. 6, pp. 93-103.

9 Colozza N., Tazzioli S., Sassolini A., Agosta L., Monte M.G., Hermansson K., Arduini F. Multiparametric analysis by paper-assisted potentiometric sensors for diagnostic and monitoring of reinforced concrete structures. Sensors and Actuators B: Chemical. 2021, Vol. 345, pp. 130352. DOI: 10.1016/j.snb.2021.130352

10 Zhang H. Building Materials in Civil Engineering: Woodhead Publishing, 2010, 441 p.

11 GOST 14254-96 Degrees of protection provided by enclosures (IP Code), 1996, 32 p.

12 GOST 16962.2-90 Electrical articles. Test methods as to environment mechanical factors stability, 1990,48 p.

13 BUD. Enclosure Design Tips Handbook: Bud Industries, Inc., 2005, 28 p.

14 Bouchard C., Aoussat A. Modellisation of the car design process. International Journal of Vehicle Design. 2003, Vol. 31, No. 1, pp. 1. doi: 10.1504/IJVD.2003.002043

15 Ivchenko A.V., Sharonov N., Ziatdinov R. New conceptual design of the adaptive compliant aircraft wing frame. Engineering Science and Technology, an International Journal. 2019, Vol. 22, No. 5, pp. 1149-1154.

16 Utepov Ye.B., Tulebekova A.S., Zharassov Sh.Zh., Abdulina S.A. Best practice in concrete strength measurement systems. Bulletin of D. Serikbayev East Kazakhstan technical university. 2021, Vol. 91, No.1, pp. 91-97.

17 Kimteks-KimyaTekstilÜrünleri Tic.A.Ş. Available at: https://www.kimteks.com.tr/en/ (13.09.2021).

$18 \mathrm{Ye}$ H. (2021) Silicone Rubber for Rapid Prototyping Available at: http://www.szrl.net /a/Products/Molding_Silicone_Rubber/Silicone_for_Prototyping/2021/0419/1742.html (accessed date: 13.09.2021).

19 GOST 15150-69 Machines, instruments and other industrial products. Modifications for different climatic regions. Categories, operating, storage and transportation conditions as to environment climatic aspects influence, 2010, 58 p.

20 Martínez S.S., Vázquez C.O., García J.G., Ortega J.G. Quality inspection of machined metal parts using an image fusion technique. Measurements. 2017, Vol. 111, pp. 374-383. DOI: 10.1016/j.measurement.2017.08.002 